\title{
A correlation analysis of isothermal crystallization of long paraffins
}

\author{
G P BAHUGUNA ${ }^{\dagger}$, V D GUPTA* and C MEHROTRA \\ Physics Department, Lucknow University, Lucknow 226007, India \\ ${ }^{\dagger}$ Physics Department, Lucknow Christian Degree College, Lucknow 226018, India \\ MS received 6 May 1994; revised 22 August 1994
}

\begin{abstract}
The small-angle X-ray scattering (SAXS) curves for ultralong $n$-alkanes obtained by Ungar and Keller at different times after reaching the crystallization temperature have been Fourier analysed. The correlation curves so obtained at different temperatures and different annealing times reflect sensitively all those morphological features which are broadly characteristic of the scattering curves. In addition the correlation curves clearly show a transition from a non-integer-fraction length to extended chain structure. Crystalline and amorphous lengths, degree of order and half-widths which characterize kinetics of morphological changes are also reported.
\end{abstract}

Keywords. Correlation function; long paraffins; morphological features; degree of order; non-integer fraction.

\section{Introduction}

Ultralong $n$-alkanes, with strictly uniform chain lengths, are ideal polymeric systems. Morphological studies on such systems have revealed important details of the crystallization behaviour of polyethylene (Keller et al 1991). In an in situ X-ray diffraction study by Ungar and Keller (1986), it was observed that the initial products of crystallization were relatively imperfect crystals, with a large disordered layer, the fold length $(l)$ being a non-integer fraction (NIF) of the fully extended chain (E) length $(L)$. Further, on isothermal crystallization, the crystal perfected itself with fold length changing to integer fraction (IF) of the chain length $L$ with the degree of surface disorder decreasing. Position correlations provide a very neat approach to morphological studies (Glatter and Kratky 1982; Vonk and Pijpers 1985; Wlochowicz et al 1992) because Fourier transform of SAXS augments the characteristic features. In the present work correlation function is used to investigate the morphological changes during NIF-IF transformation in $n$-alkane $\mathrm{C}_{246} \mathrm{H}_{494}$. The characteristic features of a series of correlation curves at different times at a certain crystallization temperature are interpreted. The degree of crystal perfection and disordered layer content are followed by calculating crystalline and amorphous lengths and crystallinity by volume. The presence of a characteristic length marks the transition from NIF to IF state. The variation of the SAXS invariant $Q$ with time and half-width of first subsidiary maximum of correlation curves enables a clearer understanding of the macromolecular crystallization.

\footnotetext{
*For correspondence
} 


\section{Theory}

\subsection{The experimental correlation function}

The intensity function $i(s)$ in reciprocal space, representing the intensity of small-angle scattering from a single region of parallel layers along normal direction, is given by

$$
i(s)=2 V \int_{0}^{\infty} \gamma^{\prime}(x) \cos (2 \pi x s) \mathrm{d} x,
$$

where

$$
\gamma^{\prime}(x)=\int_{0}^{\infty} \eta(\xi-x) \eta(\xi) \mathrm{d} \xi,
$$

and $s=2 \sin \theta / \lambda, V$ the irradiated volume of the region under consideration, $x$ the coordinate perpendicular to the layer, $\theta$ the half-angle of diffraction, $\lambda$ the wavelength of X-rays, and $\eta(\xi)$ the local fluctuations of electron density around the average value.

Fourier transformation of (1) gives

$$
\gamma^{\prime}(x)=(1 / 2 V) \int_{0}^{\infty} i(s) \cos (2 \pi x s) \mathrm{d} s
$$

and

$$
\gamma^{\prime}(0)=\left\langle\eta^{2}\right\rangle=(1 / 2 V) \int_{0}^{\infty} i(s) \mathrm{d} s,
$$

is the average of the square of the electron density fluctuations. Following Debye and Bueche (1949) we define one-dimensional correlation function as

$$
\gamma(x)=\frac{\left\langle\eta_{1} \eta_{2}\right\rangle}{\left\langle\eta^{2}\right\rangle}=\frac{\gamma^{\prime}(x)}{\gamma^{\prime}(0)} .
$$

The values of $\gamma(x)$ range from -1 to +1 .

When all orientations of the layers are present the measured intensity $I(s)$ shows spherical symmetry and the following relation can be written:

$$
I(s) \sim i(s) / 4 \pi s^{2}
$$

From (3) to (6) the position correlation function $\gamma(x)$ is given by

$$
\gamma(x)=\frac{\int_{0}^{\infty} s^{2} I(s) \cos (2 \pi x s) \mathrm{d} s}{\int_{0}^{\infty} s^{2} I(s) \mathrm{d} s} .
$$

\subsection{The correlation function calculated from a model}

A model of alternate high- and low-electron-density regions, designated as crystalline and amorphous layers respectively, proposed by Vonk and Kortleve (1967) and 
Kortleve and Vonk (1968) is used in the present analysis. Further the layers are taken to be essentially flat and parallel; however, the name crystalline or amorphous does not imply that the layer is entirely crystalline or amorphous. The thicknesses of crystalline and amorphous regions $\left(x_{\mathrm{c}}\right.$ and $\left.x_{\mathrm{a}}\right)$ are assumed to have a Gaussian distribution around the mean values $C$ and $A$. The corresponding normalized distribution functions are given by

$$
\begin{aligned}
& P_{\mathrm{c}}\left(x_{\mathrm{c}}\right)=\frac{1}{\sqrt{2 \pi}} \frac{1}{\Delta C} \exp \left[-(1 / 2)\left[\left(x_{\mathrm{c}}-C\right) / \Delta C\right]^{2}\right], \\
& P_{\mathrm{a}}\left(x_{\mathrm{a}}\right)=\frac{1}{\sqrt{2 \pi}} \frac{1}{\Delta A} \exp \left[-(1 / 2)\left[\left(x_{\mathrm{a}}-A\right) / \Delta A\right]^{2}\right],
\end{aligned}
$$

where $\Delta C$ and $\Delta A$ are widths of these functions.

Crystallinity by volume, $\phi$, is defined as

$$
\phi=\frac{C}{C+A} .
$$

The position correlation function for a two-phase model, following the method of Debye et al (1957), is given by

$$
\gamma(x)=\frac{p_{\mathrm{cc}}(x)-\phi}{1-\phi}
$$

$p_{c c}(x)$ being the probability that if one end of a hypothetical measuring rod of length $x$ is in the crystalline region then the other end is also in one of the crystalline regions. Further,

$$
p_{\mathrm{cc}}(x)=q_{\mathrm{c}}(x)+q_{\mathrm{cac}}(x)+q_{\mathrm{cacac}}(x)+\ldots,
$$

where $q$ indicates the probability with its subscript denoting the type of neighbouring layers intersected by the measuring rod.

The probability, $q_{c}(x)$, of both the ends of the measuring rod being in the same crystalline region, is given by (figure la)

$$
q_{c}(x)=(1 / C) \int_{x}^{\infty}\left(x_{c}-x\right) P_{c}\left(x_{c}\right) \mathrm{d} x_{c} .
$$

In order to make contribution to $q_{\mathrm{cac}}(x)$ the measuring rod must be positioned as in figure $1 \mathrm{~b}$.

The corresponding normalized distribution function is

$$
P_{\mathrm{cac}}(x)=\overparen{Q\left(x_{1}\right) P_{\mathrm{a}}} \overparen{\left(x_{\mathrm{a}}\right) Q\left(x_{2}\right)}
$$

in which the sign ( indicates the convolution process and $Q\left(x_{1}\right)=Q\left(x_{2}\right)$. Since a vector of length $x_{1}$ can occur only in those layers for which $x_{c}>x_{1}, Q\left(x_{1}\right)$ after normalization is given by

$$
Q\left(x_{1}\right)=(1 / C) \int_{x_{1}}^{\infty} P_{\mathrm{c}}\left(x_{\mathrm{c}}\right) \mathrm{d} x_{\mathrm{c}} .
$$




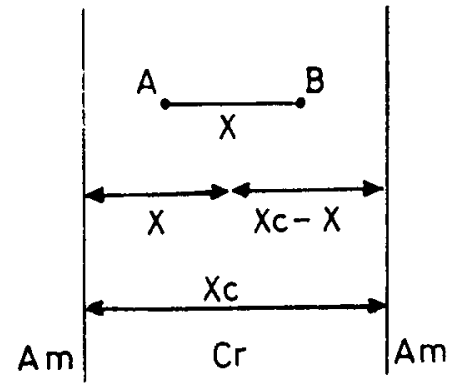

(a)

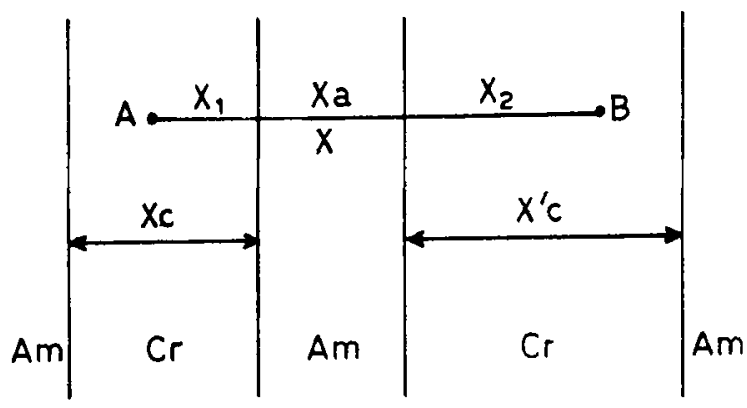

(b)

Figure 1. Positions of the measuring rod AB, which contributes to (a) $q_{\mathrm{c}}$ and (b) $q_{\mathrm{cac}}$.

It can be shown that

$$
q_{\mathrm{cac}}(x)=C P_{\mathrm{cac}}(x) .
$$

Similarly

where

$$
q_{\mathrm{cacac}}=C P_{\mathrm{cacac}}(x) \text {, }
$$

$$
P_{\text {cacac }}(x)=\widehat{Q_{\mathrm{c}}} \widetilde{P_{\mathrm{a}}} \widetilde{P_{\mathrm{c}} P_{\mathrm{a}} Q_{\mathrm{c}}} \text {, }
$$

Therefore (11) can be written as

$$
\gamma(x)=[1 /(1-\phi)]\left\{q_{\mathrm{c}}(x)+C P_{\mathrm{cac}}(x)+C P_{\mathrm{cacac}}(x)+\ldots-\phi\right\} .
$$

In the present work the situation is much simplified by the use of a theorem according to which if two variates are distributed normally their sum is also distributed normally (Pipes and Harvill 1970). This theorem has the scope of being extended to the variation of the sum of three or more variates.

Thus

$$
\begin{aligned}
\widetilde{P_{\mathrm{a}} P_{\mathrm{c}} P_{\mathrm{a}}=P_{\mathrm{a}+\mathrm{c}+\mathrm{a}}} & =\frac{1}{\sqrt{ } 2 \pi} \frac{1}{\sqrt{\left[\Delta C^{2}+2 \times \Delta A^{2}\right]}} \\
& \times \exp \left[-(1 / 2)\left(\frac{x-C-2 A}{\sqrt{ }\left[\Delta C^{2}+2 \times \Delta A^{2}\right]}\right)^{2}\right],
\end{aligned}
$$


which gives the normalized probability distribution function for the distribution of the sum of the thicknesses of two amorphous and a crystalline layer $\left(x_{\mathrm{a}}+x_{\mathrm{c}}+x_{\mathrm{a}}=x\right)$ around the mean value $A+C+A=C+2 A$.

Similarly distribution functions $P_{\text {acaca }}$ etc can be written.

Equation (18) can now be rewritten as

where

$$
\gamma(x)=[1 /(1-\phi)]\left[q_{\mathrm{c}}(x)+C P_{\mathrm{ca}}(x)-\phi\right],
$$

$$
P_{\mathrm{ca}}(x)=Q_{\mathrm{c}}\left[P_{\mathrm{a}}+P_{\mathrm{a}+\mathrm{c}+\mathrm{a}}+P_{\mathrm{a}+\mathrm{c}+\mathrm{a}+\mathrm{c}+\mathrm{a}}+\cdots\right] Q_{\mathrm{c}} \text {. }
$$

Eqn (20) is numerically solved to obtain the value of $\gamma(x)$. For this a computer program was written by us and can be provided on request. The number of terms in the square brackets of (21) depends upon the maximum length up to which the one-dimensional correlation function is to be calculated for a particular sample.

\section{Results and discussion}

The experimental curves which have been analysed are taken from the work of Ungar and Keller (1986). These curves are recorded at different times after reaching a fixed crystallization temperature. In Ungar and Keller's experimental set-up, the long dimension of the beam was parallel to the sample capillary. The primary beam intensity was monitored and corrected for variation throughout. No slit desmearing was found necessary. The quantitative data from Ungar and Keller's curves are generated by Fourier-transforming them. Corresponding correlation curves are shown in figures 2-4. The various parameters are presented in tables $1-3$ (the data correspond to the curves obtained after smoothening the computer-plotted curves).

General examination of the correlation curves at a higher temperature of $120.5^{\circ} \mathrm{C}$ (figure 2) and data in column 2 of table 1 reveal that in the first $2.5 \mathrm{~min}$ the long spacing $(D)$ increases from $208 \AA$ to $228 \AA$ and the peak height of first subsidiary maximum diminishes showing a transient state of thickening in which the sample behaves as an aggregate of crystallites of varying thicknesses resulting in a low value of correlation function. At 3 min the presence of two clear-cut components of different thicknesses can be made out from a shoulder at $208 \AA$ and a new peak (peak 2) at $252 \AA$. From here onwards the shoulder gradually becomes less pronounced and finally disappears showing that the transformation of NIF state is complete. Simultaneously the height and sharpness of the second peak reaching a maximum shows the near perfection of the newly emerged $E$ state. All through the first minimum, the correlation curve broadens and its depth decreases showing ordering effect.

A perusal of the data given in table 1, column 5 shows a steady increase in the crystalline length $(C)$ and a decrease in the value of $A / D$ from 0.43 in the beginning to 0.27 at $7 \mathrm{~min}$. Thus the amorphous layer thickness fraction $(A / D)$ is maximum for the initial NIF state and its value is much reduced in the final IF state. The same trend can be inferred from the change in the value of degree of order (crystallinity by volume $\phi$; column 3 , table 1 ) from 0.57 to a final value of 0.735 .

As soon as a sample reaches the melting temperature, the crystallization is initiated by the formation of nuclei and sharply defined fold lengths. The scattering curve at this stage is also narrow and broadens with time but as soon as the structure reaches an extended chain structure it is again narrow (Ungar and Keller 1986). The 


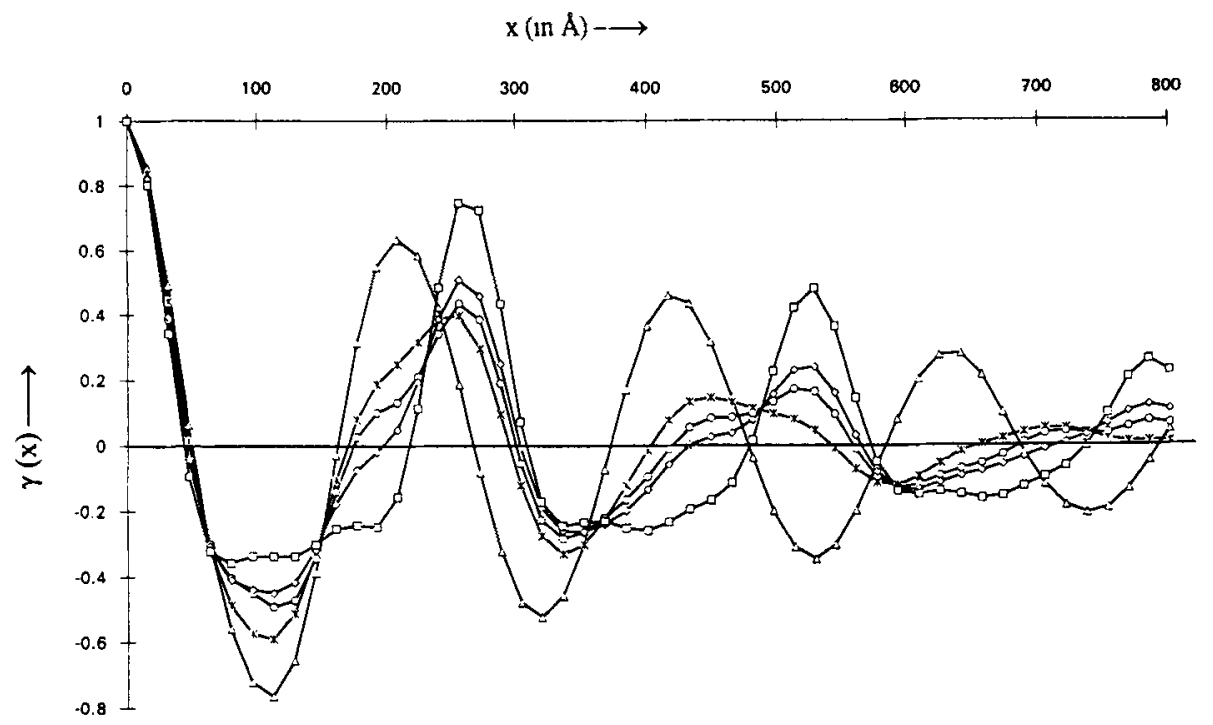

Figure 2. Experimental correlation curves of $\mathrm{C}_{246} \mathrm{H}_{494}$ at various times after reaching the crystallization temperature $120.5^{\circ} \mathrm{C}: 1.0 \mathrm{~min}(\Delta), 3.0 \mathrm{~min}(*), 3.5 \mathrm{~min}(O), 4.0 \mathrm{~min}(\diamond)$ and $7.0 \mathrm{~min}(\square)$.

Table 1. Crystallization temperature $120 \cdot 5^{\circ} \mathrm{C}$.

\begin{tabular}{|c|c|c|c|c|c|c|c|c|c|c|}
\hline \multirow[b]{2}{*}{$\begin{array}{l}\text { Time } \\
(\mathrm{min})\end{array}$} & \multicolumn{2}{|c|}{$\begin{array}{l}\text { Position of } \\
\text { first subs. } \\
\max .(\AA)\end{array}$} & \multirow{2}{*}{$\begin{array}{l}\text { Degree of } \\
\text { order (Crystalli- } \\
\text { nity by volume) }\end{array}$} & \multirow{2}{*}{$\begin{array}{l}\text { Inverse of full } \\
\text { width at half } \\
\text { height of first } \\
\text { subs. } \max \text {. } \\
\left(\times 10^{-2} \AA^{-1}\right)\end{array}$} & \multicolumn{6}{|c|}{$\begin{array}{l}\text { Parameters characteristic of two phase } \\
\text { parallel layer model }\end{array}$} \\
\hline & $\begin{array}{c}\text { Peak } \\
1\end{array}$ & $\begin{array}{c}\text { Peak } \\
2\end{array}$ & & & $\begin{array}{c}D \\
(\AA)\end{array}$ & $\begin{array}{l}C \\
(\AA)\end{array}$ & $\begin{array}{c}A \\
(\AA)\end{array}$ & $A / D$ & $\begin{array}{c}\Delta C / C \\
(\times 100)\end{array}$ & $\begin{array}{c}\Delta A / A \\
(\times 100)\end{array}$ \\
\hline 1.0 & 208 & - & 0.570 & 1.39 & 208 & 118.6 & $89 \cdot 4$ & 0.43 & $15 \cdot 1$ & $14 \cdot 3$ \\
\hline 1.5 & 208 & - & 0.570 & 1.39 & 208 & 118.6 & $89 \cdot 4$ & 0.43 & $17 \cdot 4$ & $16 \cdot 3$ \\
\hline $2 \cdot 0$ & 208 & - & 0.587 & 1.28 & 208 & $122 \cdot 1$ & 85.9 & 0.41 & $21 \cdot 5$ & 18.6 \\
\hline 2.5 & 228 & - & 0.610 & $1 \cdot 14$ & 228 & $139 \cdot 1$ & 88.9 & 0.39 & $29 \cdot 5$ & 18.9 \\
\hline 3.0 & 208 & 252 & 0.630 & 1.25 & 252 & 158.8 & $93 \cdot 2$ & 0.37 & $28 \cdot 8$ & $20 \cdot 2$ \\
\hline 3.5 & 208 & 256 & 0.670 & 1.67 & 256 & $171 \cdot 5$ & $84 \cdot 5$ & 0.33 & $24 \cdot 4$ & $21 \cdot 6$ \\
\hline 4.0 & 208 & 260 & $0-690$ & 1.73 & 260 & 179.4 & $80 \cdot 6$ & 0.31 & $22 \cdot 0$ & $20 \cdot 1$ \\
\hline 7.0 & - & 264 & 0.735 & 2.08 & 264 & 1940 & $70 \cdot 0$ & 0.27 & 9.2 & $15 \cdot 2$ \\
\hline
\end{tabular}

correlation curves reflect this more sensitively, though in an inverse manner, due to the nature of Fourier transform. The inverse width of the first subsidiary maximum at half height (table 1, column 4) first decreases and then increases, thus lending support to the above fact.

The common meeting point of the various correlation curves drawn for various transient states of crystallization (at different times) shows the presence of a characteristic length which marks transition from the NIF to E state. This length is midway between the NIF and E lengths. This is better shown in figure 5 ( $D$ value vs time plot). The presence of meeting points in the negative and positive half of the correlation curve reflects only the damped oscillatory behaviour of the correlation curves. 


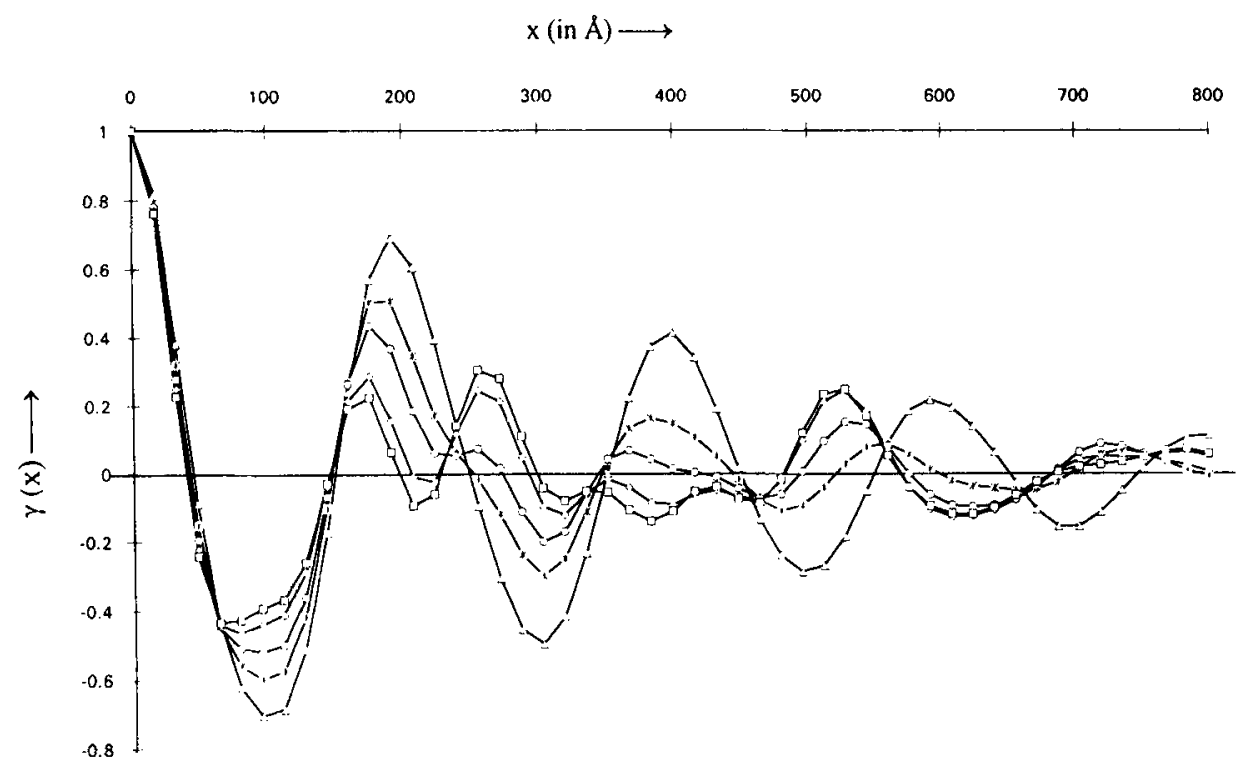

Figure 3. Experimental correlation curves of $\mathrm{C}_{246} \mathrm{H}_{494}$ at various times after reaching the crystallization temperature $117.8^{\circ} \mathrm{C}: 1.5 \mathrm{~min}(\Delta), 3.0 \mathrm{~min}(*), 4.0 \mathrm{~min}(O), 6.0 \mathrm{~min}(\diamond)$ and $8.0 \min (\square)$.

Table 2. Crystallization temperature $117 \cdot 8^{\circ} \mathrm{C}$.

\begin{tabular}{|c|c|c|c|c|c|c|c|c|}
\hline \multirow[b]{2}{*}{$\begin{array}{l}\text { Time } \\
(\mathrm{min})\end{array}$} & \multicolumn{2}{|c|}{$\begin{array}{l}\text { Position of } \\
\text { first subs. } \\
\max (\mathbb{A})\end{array}$} & \multirow{2}{*}{$\begin{array}{l}\text { Degree of } \\
\text { order (crystalli- } \\
\text { nity by volume) }\end{array}$} & \multirow{2}{*}{$\begin{array}{l}\text { Inverse of full } \\
\text { width at half } \\
\text { height of first } \\
\text { subs. max. } \\
\left(\times 10^{-2} \AA^{-1}\right)\end{array}$} & \multicolumn{4}{|c|}{$\begin{array}{l}\text { Parameters characteristic of } \\
\text { two-phase parallel layer mode }\end{array}$} \\
\hline & $\begin{array}{c}\text { Peak } \\
1\end{array}$ & $\begin{array}{c}\text { Peak } \\
2\end{array}$ & & & $\begin{array}{c}D \\
(\AA)\end{array}$ & $\begin{array}{c}C \\
(\AA)\end{array}$ & $\begin{array}{c}A \\
(\AA)\end{array}$ & $A / D$ \\
\hline $1 \cdot 5$ & 192 & - & 0.587 & 1.56 & 192 & $112 \cdot 7$ & $79 \cdot 3$ & 0.41 \\
\hline $2 \cdot 0$ & 192 & - & 0.593 & 1.61 & 192 & 113.9 & $78 \cdot 1$ & 0.41 \\
\hline $2 \cdot 5$ & 188 & - & 0.610 & 1.73 & 188 & $114 \cdot 7$ & $73 \cdot 3$ & $0 \cdot 39$ \\
\hline $3 \cdot 0$ & 184 & - & 0.625 & $2 \cdot 00$ & 184 & $115-0$ & $69 \cdot 0$ & $0 \cdot 38$ \\
\hline 3.5 & 182 & 240 & 0.631 & 200 & 240 & $151 \cdot 4$ & 88.6 & 0.37 \\
\hline $4 \cdot 0$ & 176 & 256 & 0.658 & $2 \cdot 08$ & 256 & $168 \cdot 4$ & 87.6 & 0.34 \\
\hline 5.0 & 176 & 256 & 0.673 & $2 \cdot 50$ & 256 & $172 \cdot 3$ & 83.7 & 0.33 \\
\hline 6.0 & 176 & 260 & 0.683 & $2 \cdot 50$ & 260 & $177 \cdot 6$ & 82.4 & $0 \cdot 32$ \\
\hline 8.0 & 172 & 264 & 0.697 & $2 \cdot 50$ & 264 & $184 \cdot 0$ & $80 \cdot 0$ & $0 \cdot 30$ \\
\hline
\end{tabular}

Correlation curves at $117.8^{\circ} \mathrm{C}$ (figure 3), a somewhat lower temperature, and corresponding data in table 2 show the transformation occurring slowly. The two subsidiary maximum peaks can be seen clearly even after $8 \mathrm{~min}$. The $\mathrm{E}$ structure is emerging steadily and perfecting itself slowly. The spacing of the still untransformed part is slowly decreasing and tending to the spacing corresponding to the once folded structure. The fact that the height of peak 1 decreases continuously shows that the 
choice of acquiring an extended chain structure seems to be the most preferred one leading to a final $E$ structure. It is further confirmed by the presence of a prominent second subsidiary maximum at $520 \AA$. The positive values of the correlation function at the two meeting points of the curves at $152 \AA$ and $240 \AA$ (average value) indicate the tendency of the system to either fold in two (F2 structure) or have extended chain disposition (E structure).

At a still lower temperature of $106^{\circ} \mathrm{C}$ the correlation curves (figure 4 , also table 3 ) indicate the further slowing down of the NIF-IF transformation. The common meeting point of curves at about $164 \AA$ shows that a decrease of the repeat distance will follow, leading to a once folded structure in this case.

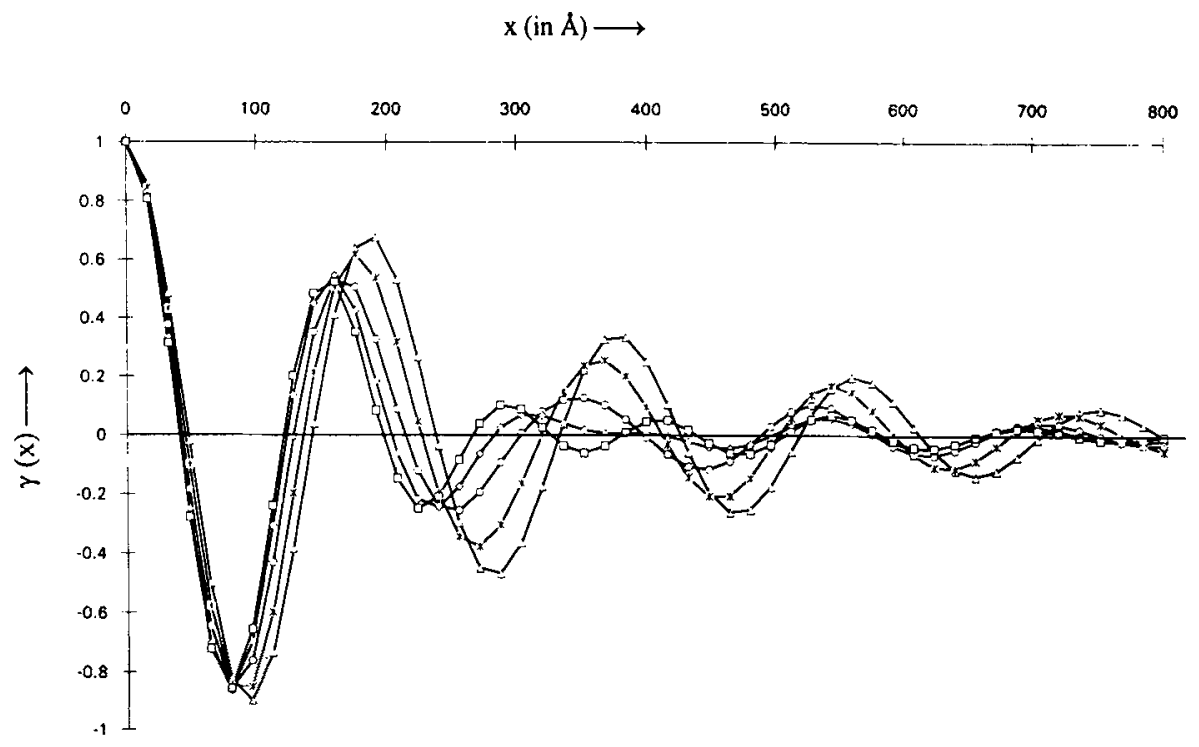

Figure 4. Experimental correlation curves of $\mathrm{C}_{246} \mathrm{H}_{494}$ at various times after reaching the crystallization temperature $106^{\circ} \mathrm{C}: 0.2 \mathrm{~min}(\Delta), 2.5 \mathrm{~min}(*), 8.5 \mathrm{~min}(O), 18.0 \mathrm{~min}(\diamond)$ and $33.0 \mathrm{~min}(\square)$.

Table 3. Crystallization temperature $106 \cdot 0^{\circ} \mathrm{C}$.

\begin{tabular}{|c|c|c|c|c|c|c|c|c|}
\hline \multirow[b]{2}{*}{$\begin{array}{l}\text { Time } \\
(\min )\end{array}$} & \multicolumn{2}{|c|}{$\begin{array}{l}\text { Position of } \\
\text { first subs. } \\
\text { max. }(\AA)\end{array}$} & \multirow{2}{*}{$\begin{array}{l}\text { Degree of } \\
\text { order (crystalli- } \\
\text { nity by volume) }\end{array}$} & \multirow{2}{*}{$\begin{array}{l}\text { Inverse of full } \\
\text { width at half } \\
\text { height of first } \\
\text { subs. max. } \\
\left(\times 10^{-2} \AA^{-1}\right)\end{array}$} & \multicolumn{4}{|c|}{$\begin{array}{l}\text { Parameters characteristic of } \\
\text { two-phase parallel layer model }\end{array}$} \\
\hline & $\begin{array}{c}\text { Peak } \\
1\end{array}$ & $\begin{array}{c}\text { Peak } \\
2\end{array}$ & & & $\begin{array}{c}D \\
(\AA)\end{array}$ & $\begin{array}{l}C \\
(\AA)\end{array}$ & $\begin{array}{c}A \\
(\AA)\end{array}$ & $A / D$ \\
\hline 0.2 & 188 & - & 0.526 & 1.56 & 188 & 98.9 & $89 \cdot 1$ & 0.474 \\
\hline $2 \cdot 5$ & 176 & - & 0.538 & 1.67 & 176 & $94 \cdot 7$ & $81 \cdot 3$ & 0.462 \\
\hline $8 \cdot 5$ & 164 & - & 0.540 & 1.73 & 164 & $88 \cdot 6$ & $75 \cdot 4$ & 0.460 \\
\hline 18.0 & 160 & - & 0.537 & 2.00 & 160 & 85.9 & $74 \cdot 1$ & 0.463 \\
\hline 33.0 & 152 & - & 0.540 & 2.08 & 152 & $82 \cdot 1$ & $69-9$ & 0.460 \\
\hline
\end{tabular}


Thus the correlation approach shows that the transformation of the metastable NIF state to a more ordered and more stable extended state takes place by the thickening of the lamellae and the thinning of the disordered layer surface (at $120.5^{\circ} \mathrm{C}$ and $117.8^{\circ} \mathrm{C}$ ) while in case of transformation to once folded state a decrease in long spacing takes place mainly by a decrease in the value of amorphous length. The process is known in polymers as secondary crystallization.

Figures 6 and 7 show a plot of integrated SAXS intensity vs time at fixed temperatures $120.5^{\circ} \mathrm{C}$ and $117.8^{\circ} \mathrm{C}$. The fact that the invariant $Q$ first increases and then decreases indicates that during isothermal crystallization the ratio between the thicknesses of amorphous and crystalline layers decreases.

In their work on $\mathrm{C}_{246} \mathrm{H}_{494}$ Ungar and Keller (1987) have shown that the stepping up of the primary crystal growth rate of extended chain crystals is triggered by the isothermal F-E transformation at about $121.2^{\circ} \mathrm{C}$, the transition temperature between extended and folded chain crystallization. Therefore in the present temperature range

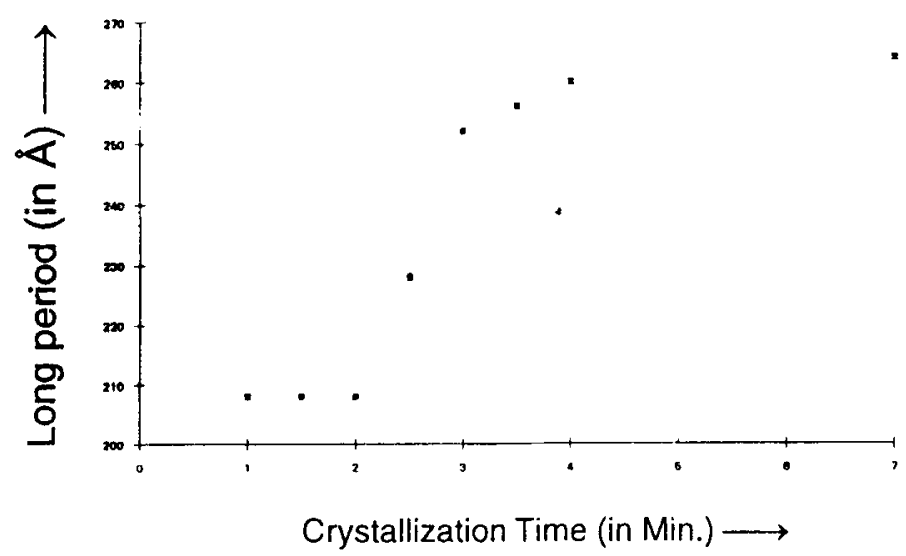

Figure 5. Long period vs crystallization time plot for isothermal crystallization of $\mathrm{C}_{246} \mathrm{H}_{494}$ at $120 \cdot 5^{\circ} \mathrm{C}$.

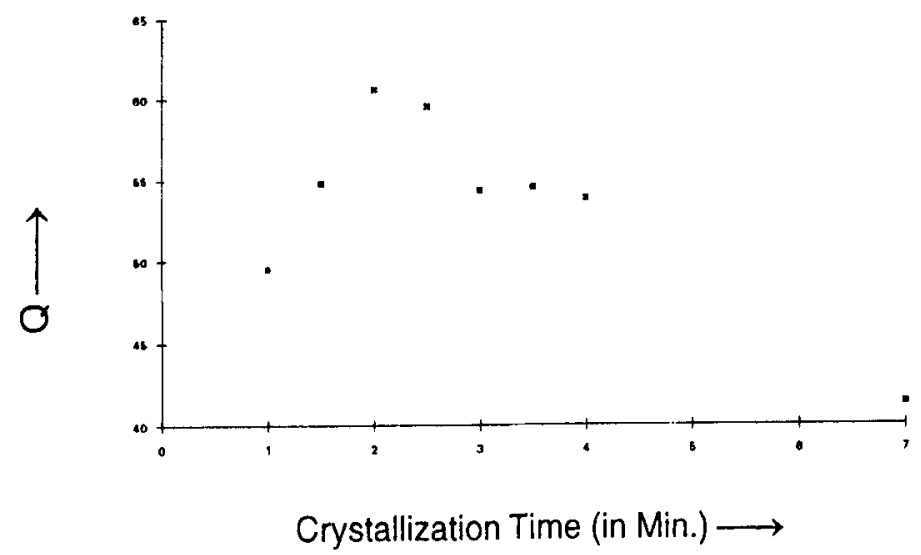

Figure 6. SAXS invariant $(Q)$ vs crystallization time plot for isothermal crystallization of $\mathrm{C}_{246} \mathrm{H}_{494}$ at $120 \cdot 5^{\circ} \mathrm{C}$. 


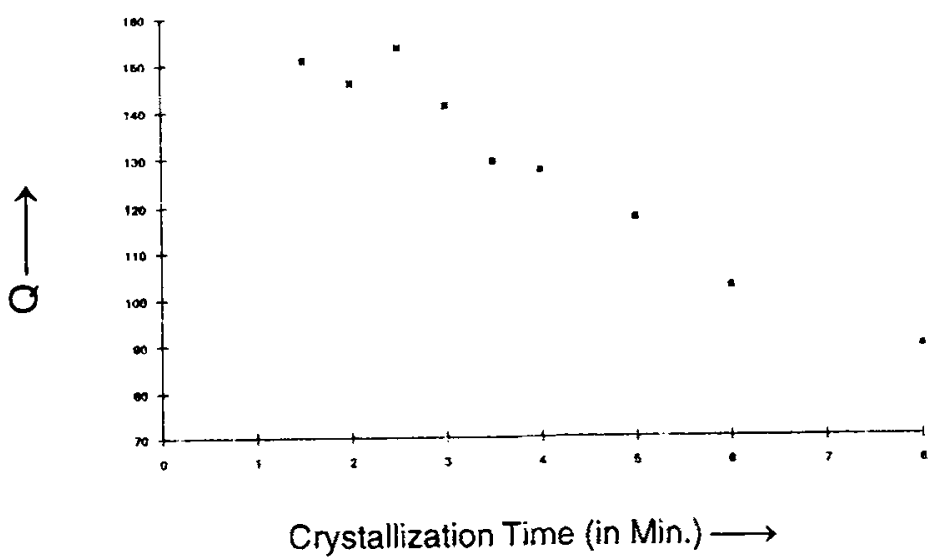

Figure 7. SAXS invariant $(Q)$ vs crystalljzation time plot for isothermal crystallization of $\mathrm{C}_{246} \mathrm{H}_{494}$ at $117 \cdot 8^{\circ} \mathrm{C}$.

the E-chain form is the result of thickening of the initially formed crystals and not of direct crystallization. The perfection is thus the result of an increase in crystallinelayer fraction of the crystal with a concomitant decrease of noncrystalline-layer fraction.

The degree of order or disorder obtained from the correlation function includes the order or disorder present in the folds. As the system makes a transition to the extended state, the order increases. For a tight fold on the surface a minimum of ten repeat units at both the ends are necessary (Young 1986) and in tight folding the chains would become part of the ordered state. The disordered state would really arise from the fold lengths greater than ten (at both the ends) and these will constitute loose ends in fold length.

A possible explanation of the thickening of the lamellae in the above manner is that the sliding diffusion of the molecular chains along their axes compacts them in the crystalline layer of the crystal to the surface of which they are attached, as in the case of trans-1,4-polybutadiene (Tatsumi et al 1967). A molecular kink, a unique type of point defect for macromolecules (Young 1986), moving along the chain may be the mechanism of crystal thickening.

The presence of a disordered layer surface all through the isothermal crystallization from NIF to IF state (at temperatures examined) shows that there are at least some of the folds which, being linked with different crystalline regions, remain so even after the crystal has perfected itself.

The experimental studies have also been compared with the theoretical calculations from the parallel-layer model of Vonk and Kortleve (1967) and Kortleve and Vonk (1968). The parameters of the model, viz. the crystalline and amorphous lengths and their log normal widths, were varied to obtain best fits of theoretical curves to the corresponding experimental ones. As a representative of the match between the experimental results and theoretical model we show in figures 8-11 the correlation curves for the experimental data of $\mathrm{C}_{246} \mathrm{H}_{494}$ at $120.5^{\circ} \mathrm{C}$ at $1.0,2.5,3.0$ and $7.0 \mathrm{~min}$ after reaching the temperature of crystallization and theoretical model of crystalline and amorphous lengths and their widths of distribution respectively. The following conclusions could be drawn: 


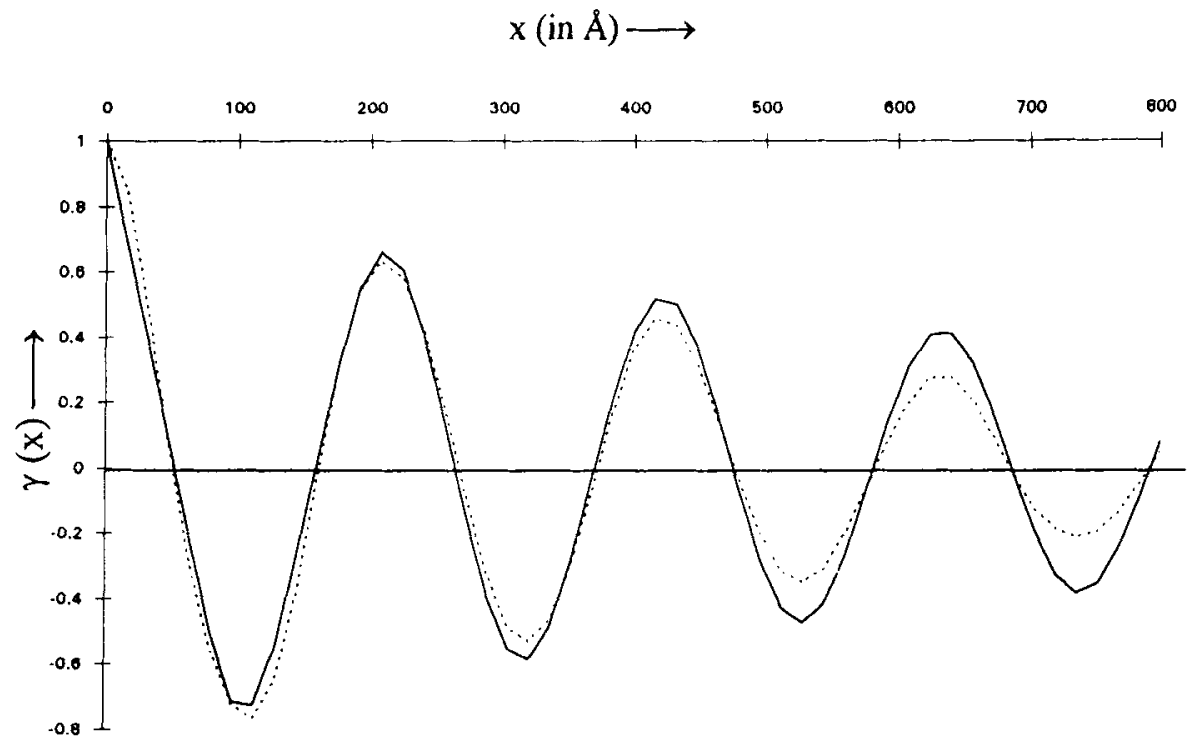

Figure 8. Experimental (--) and theoretical (-) correlation curves at $1.0 \mathrm{~min}$ after reaching the crystallization temperature $120.5^{\circ} \mathrm{C}$.

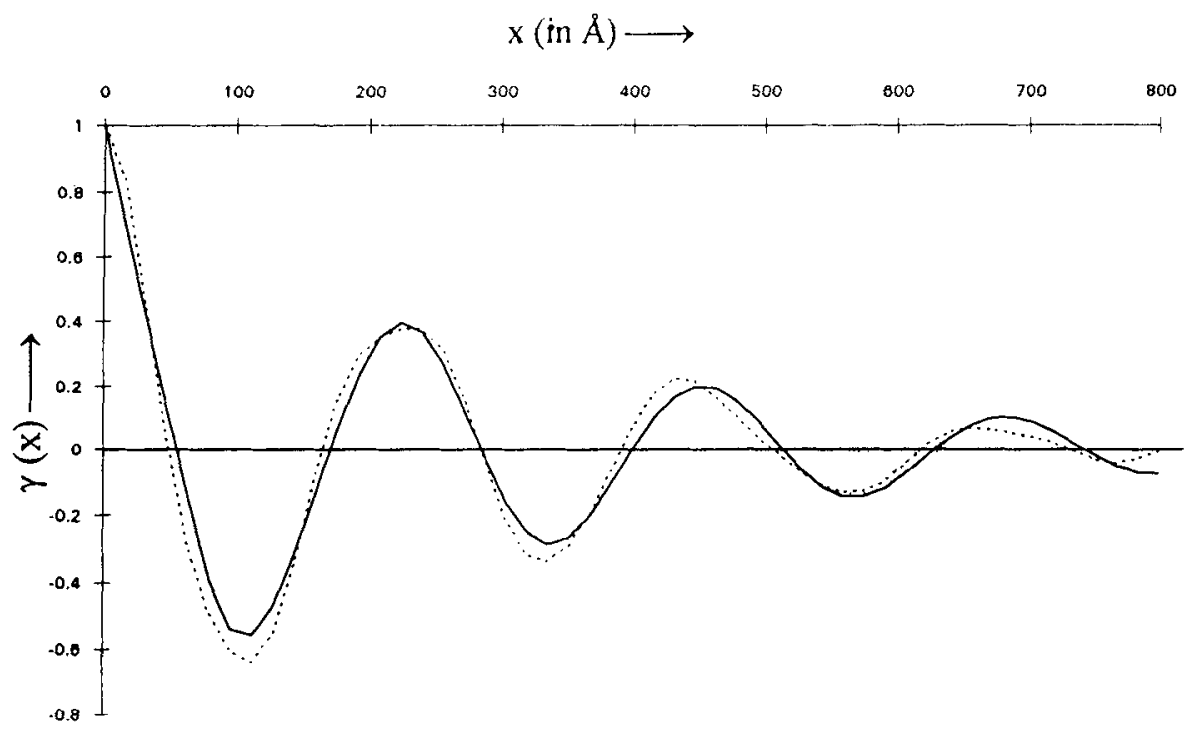

Figure 9. Experimental (--) and theoretical $(-)$ correlation curves at $2.5 \mathrm{~min}$ after reaching the crystallization temperature $120 \cdot 5^{\circ} \mathrm{C}$.

(i) A fairly good agreement between the theoretical and experimental curves shows the suitability of the model for the calculations of the valious parameters. However there are some deviations for larger correlation lengths.

(ii) The matching between the theoretical and experimental curves gets better with isothermal crystallization time ( 1.0 to $2.5 \mathrm{~min})$ till the system is ripe for transformation. During NIF-IF transformation the system is in nonequilibrium state with distorted 


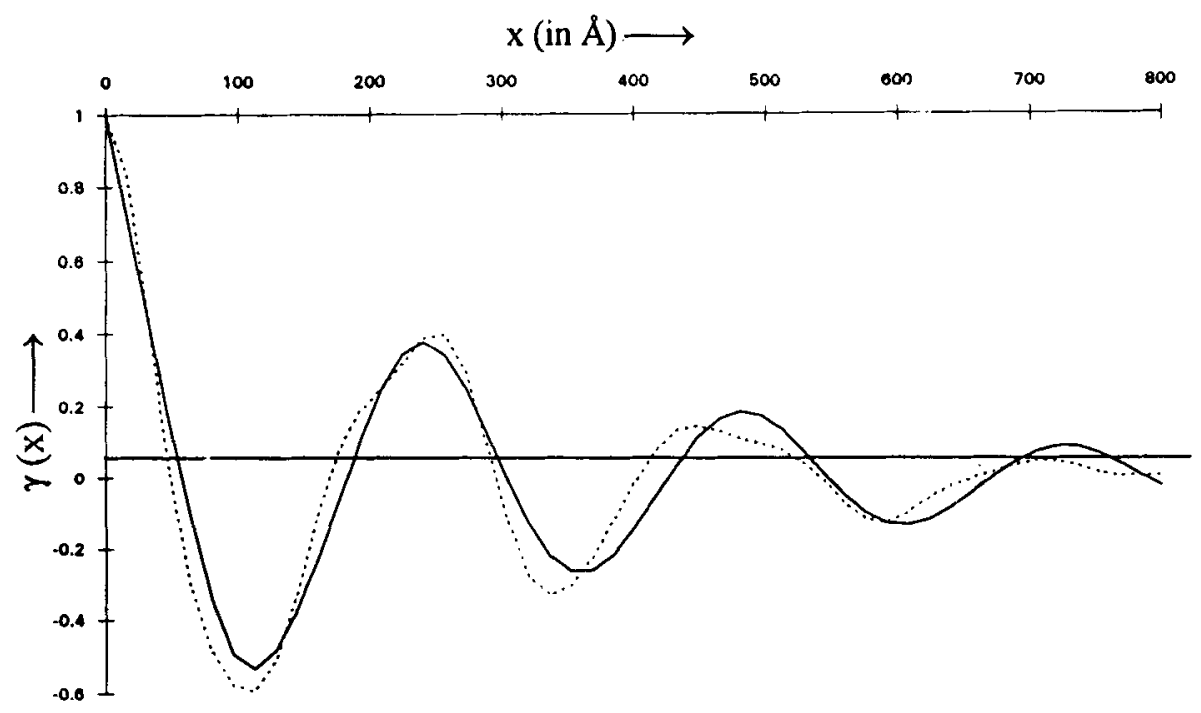

Figure 10. Experimental (--) and theoretical $(-)$ correlation curves at $3.0 \mathrm{~min}$ after reaching the crystallization temperature $120 \cdot 5^{\circ} \mathrm{C}$.

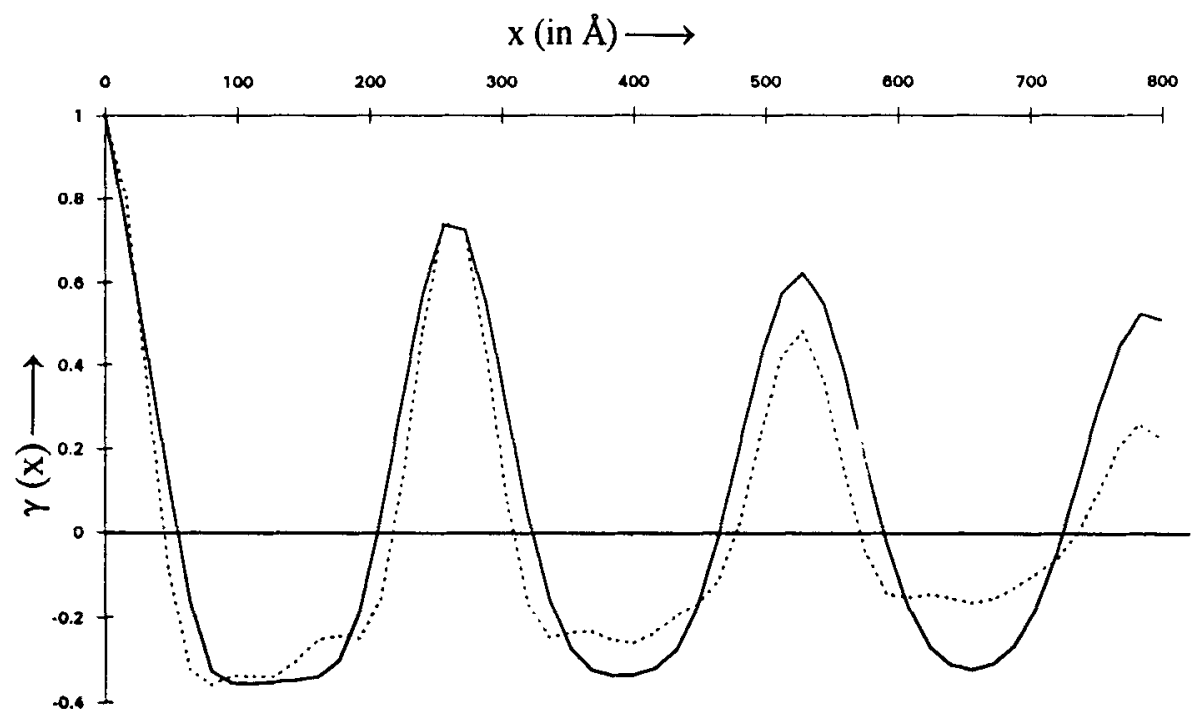

Figure 11. Experimental (--) and theoretical $(-)$ correlation curves at $7.0 \mathrm{~min}$ after reaching the crystallization temperature $120 \cdot 5^{\circ} \mathrm{C}$.

layer surfaces and as expected does not follow the model. The matching is excellent at $7.0 \mathrm{~min}$ at least up to first subsidiary maximum showing the emergence of a perfected IF structure (Ungar and Keller 1986).

The variation of the width of distribution of crystalline layer, which is the wider of the two layers, given by the parameter $\Delta C / C \times 100$ (table 1, column 5), brings out clearly the fact that isothermal crystallization leads to a more stable and perfect IF structure (Ungar and Keller 1986).

(iii) The fact that the experimental correlation curves show a greater damping than 
the theoretical ones indicates that to assign a constant value to the width of distribution of the layer thicknesses is not wholly justified owing to the nonparallelism and nonsmoothness of the layer surfaces (Vonk 1973).

The nonzero value of $\left[\partial^{2} \gamma(x) / \partial x^{2}\right]$ at origin indicates the probability of a transition layer but due to the limited accuracy of the correlation curves in this region this could not be taken into account.

Notwithstanding the above factors the present analysis lends support to the two-phase concept of a polymer.

A detailed study on the theoretical matching of the experimental calculations will be reported in a communication to follow

\section{Acknowledgements}

Financial assistance to GPB from the University Grants Commission under the Teacher Fellowship Scheme and to VDG from the Council of Scientific and Industrial Research under the Emeritus Scientist Scheme is gratefully acknowledged.

\section{References}

-Debye P, Anderson H R Jr and Brumberger H 1957 J. Appl. Phys. 28679

Debye P and Bueche A M 1949 J. Appl. Phys. 20518

Glatter $O$ and Kratky $O 1982$ Small angle $X$-ray scattering (New York: Academic Press)

Keller A, Organ S J and Ungar G 1991 Makromol. Chem., Macromol. Symp. 93

Kortleve G and Vonk C G 1968 Kolloid-Z. 225124

Pipes L A and Harvill L R 1970 Applied mathematics for engineers and physicists (McGraw-Hill Kogakusha Ltd.) 3rd ed. pp 757-758

Tatsumi T, Fukushima T, Imada K and Takayanagi M 1967 J. Macromol. Sci.-Phys. B1 459

Ungar G and Keller A 1986 Polymer 271835

Ungar G and Keller A 1987 Polymer 281899

Vonk C G 1973 J. Appl. Cryst. 681

Vonk C G and Kortleve G 1967 Kolloid-Z. 22019

Vonk C G and Pijpers A P 1985 J. Polym. Sci. Polym. Phys. Ed. 232517

Wlochowicz A, Slusarczyk C, Narebska A and Szymanski G 1992 J. Macromol. Sci.-Phys. B31 239

Young R J 1986 Introduction to polymers (London: Chapman and Hall) pp. 165, 181 